Journal of Education and Vocational Research

Vol. 5, No. 4, pp. 239-246, December 2014 (ISSN 2221-2590)

\title{
Model of Entrepreneurship Learning in Growing New Entrepreneur (Case Study in Centre of Business Incubator, West Java, Indonesia)
}

\author{
*Sri Hartati, Wawan Dhewanto, Rendra Chaerudin, Lenny Martini \\ School of Business and Management ITB, Bandung, Indonesia \\ *sri.hartati@sbm-itb.ac.id
}

\begin{abstract}
The increasing number of unemployment and poverty led to increasingly perceived importance of entrepreneurship. Development will go well if supported by business because the government is very limited capabilities. Therefore, an entrepreneur development is potential both in number and quality. The fact is that the number of entrepreneurs facing Indonesia is still small and the quality was still low, so that entrepreneurship development is an urgent issue for the success of development. Therefore, model of entrepreneurship learning for new entrepreneur growth is very necessary. This study aims to obtain a model of entrepreneurial learning in entrepreneurial business growth through the use of methods, techniques and learning aids, determination of material and the effect on the growth of entrepreneur business. The study was conducted by using descriptive research and verification research. Unit of analysis is the institution of education providers that have business incubator, both public and private training. The success of entrepreneurial learning process is carried out by taking into account various factors, namely:Iinstructor,Course to be delivered,Methode that use, techniques and tools that will be used and the feedback is expected to learning process.The criteria used for the selection of prospective entrepreneurs consists of three criteria such as:motivation, entrepreneurship skills and business skills.The results showed that the model of learning effective and efficient learning must be adapted to need entrepreneur business include instructors, materials, techniques and tools which is used. This will affect the success of the learning activities in developing or growing entrepreneurial business.
\end{abstract}

Keyword: Model entrepreneurship learning, entrepreneur, incubator, methode and business

\section{Introduction}

Problem back ground: The problem of unemployment and poverty is still a major problem faced by Indonesia today and the next few years. The unemployment rate jumped from $6.08 \%$ in 2000 to $9.86 \%$ in 2004 , and continued to rise to $10.4 \%$ in 2006. It is only since the year 2007 there was a slight decline. The number of unemployed fell from 10.55 million people (9.7\%) in 2007 to 9.43 million people (8.5\%) in 2008 and became 9.26 million people (8.1\%) in 2009. The Central Bureau of Statistics (BPS) said Indonesia's open unemployment rate in February 2012 reached $6.32 \%$, or 7.61 million people. This number is down 6\% from February 2012 which amounted to 8.12 million people.While in terms of the number of unemployed decreased until February 2013, as many as 70,000 people when compared to August 2012 and decreased 440,000 compared to February 2012. Despite the decrease in the unemployment rate, but the government should continue to promote the creation of his employment. The Government has committed to lowering the unemployment rate to about $5 \%$ and the poverty rate to around $8 \%$ in 2014 . The government also has targeted economic growth of 7\% per year. By relying only feared the growth of unemployment and poverty problems are difficult to overcome and difficult to achieve government targets. Therefore, to overcome unemployment and poverty in Indonesia needs to be directed through the creation of employment opportunities indirectly in the form of growing new entrepreneurs, both business and family or small business.

To achieve our target and above target, the government through the Ministry and the Agency launched various programs to reduce unemployment among other programs Entrepreneurial Growth and Development Degree and National Entrepreneurship Movement (GKN). GKN triggered through the Ministry of Cooperatives and SMEs predicts a growing number of national entrepreneurship development based on the ratio of the last 3 years to reach about $2.5 \%$ of the population, or as many as $6,128,655$ people. To 
increase the number of entrepreneurs is directed by relying on the younger generation. The capacity and quality of the younger generation could determine the future development of the nation. While the number of youth aged 16-30 years earning a great potential. The success of the various programs implemented in the growth of self-employment must have been influenced by various factors, among others, in the process of growing a sustainable entrepreneurial and have not done learning curriculum more focused on the technical aspects, while aspects of entrepreneurial management is still lacking.

\section{Literature Rivieuw}

Learning Methode: Based on studies Shard and Poland (1987), said that the business education to prepare students to enter the business work skillfully, equally important, to prepare students to lead business competition they have, and as a smart consumer, and as citizens who are good in science business economics. From this restriction limits can be concluded that business education in the United States is directed to:

- $\quad$ prepare students as skilled workers in the business world

- to prepare students as a reliable business person

- Prepare students as consumers are rational

- to promote their students to master the business economics

In connection with preparing the students as a business, cannot be separated with the creation of entrepreneurs. Schumpeter in Entrepreneurship, said an entrepreneur is an individual who had the opportunity and creates an organization to pursue (pursue opportunities). Eentrepreneur are always looking for change, respond to it and use it as an opportunity. Therefore, we can say that an entrepreneur is a person who loves change, because the change in the opportunity is always there. He will always pursue these opportunities by establishing an organization. As an entrepreneurial process involves all the functions, activities, and measures related to acquisition opportunities and the creation of organizations to pursue them. Therefore, if the mission is to implement education business entrepreneur education, then it is proper curriculum and learning strategy of change and adjustment. Seeing the characters above entrepreneurs, entrepreneurs seem hard formation is reached, when the learning process is still using a strategy that virtually "classic".

According Politis (2005), the entrepreneur is the result of learning. Although the spirit of entrepreneurs may also be obtained from birth as a talent, but if not sharpened through learning and motivated in the learning process, perhaps like a dull knife. To sharpen the interest and ability of entrepreneurs needs to be fostered and developed through a process of learning and teaching. Herein lays the importance of education and entrepreneurs in business education. Apart from the above, in fact since the early 19th century (Todaro, 1997) in the theory of economic growth has been said, that in addition to the capital stock and technology has brought economic growth, one thing that is no less important is an entrepreneur. He argues that the world has emerged pioneers of economic growth, which is the expertise and creativity have evolved economic growth, the entrepreneur. Many emerging world-class entrepreneurs have been born, who can make changes to the global economic order. Learning is an auto activity undertaken by the students in this course. This is receive materials related to the learning process performed. Learning is a process that occurs gradually (episodes). Stages consist of information, transformation, and evaluation. Information concerning the material that will be taught, with regard to the transformation process moving materials, and evaluation of an activity that is done to see the extent to which the success of the process that has been undertaken by learners and teachers. Center for Curriculum Research and Development Ministry of Education states that the Teaching and Learning Activities (KBM) is an active process for students and teachers for develop the potential of students so that they will "know" to knowledge and finally "able" to do something. The basic principle of teaching is to empower all of the students so that they will be able to increase his understanding of the facts / concepts / principles learned in the study of science that will be seen in the ability to think logically, critically, and creatively (Curtis, Finch \& Crunklin, 1999)

Learning is a process of interaction of students with teachers and learning resources in a learning environment. Learning is the assistance provided educators to be a process of knowledge acquisition and knowledge, mastery of skills and qualities, and the formation of attitudes and beliefs on the learner. In other 
words, learning is a process to help learners to learn well. Lifelong learning process experienced by a human as well as applies wherever and whenever (Yager, 2001)

Types of Learning:

a. Troubleshooting problems means the act of responding to a pressing problem to take advantage of opportunities due to poor or benefit that. Problem solving is an action taken so that students motivated teachers to accept the challenges that exist in the questions and directing students in the solution process.

b. Worksheet. Worksheet is one way and the variations so that students can be more active during the learning process. The worksheet is a sheet of copy distributed to each student teacher in a classroom to do activities / learning activities.

c. A Case Study: Model Missouri Mathematics Project (MMP) MMP is a learning model that includes these steps: introduction or review, development, teacher-training, self-employment and cover (make a summary of the lesson, make reflections on the good things that have been performed as well as the less good things that should be eliminated).

d. NHT (Numbered Heads Together) NHT is one type of cooperative learning models, which is a method of learning in which each student is given a number and then created a group and then randomly call numbers of student teachers.

e. Improving learning approach

Entrrepreneurship Model: Entrepreneurship is defined as the science of "how, by whom, and with what effects opportunities to create goods and services in the future discovered, evaluated, and exploited" (Shane and Venkataraman, 2000) and the innovation needed to transform opportunities into products or services. provides three sets of questions as a guide to the study of entrepreneurship: (1) why, when, and how opportunities for the creation of goods and services to be; (2) why, when, and how some people and not others discover and exploit opportunities; and (3) why, when, and how the different measures used to exploit entrepreneurial opportunities. (4) results at the industry level and the community should be considered as well. Entrepreneurial process should be considered to understand the four sets of questions above. One model that is commonly used as a comprehensive approach to the process of entrepreneurship is the Timmons model (Figure 2.3). According to Timmons and Spinneli (2007), the entrepreneurial process starts from the opportunities, backed by resources, and is balanced by the team. Characteristics of a good opportunity viewed from three cases, the market demand (market demand), the structure and size of the market (market structure and size), and the analysis of the difference (margin analysis). The resources needed in the process of entrepreneurship include financial, assets, people, and business plans. Tim is a stabilizing factor in the entrepreneurial process, because a good team will be able to manage the balance between opportunities and resources.

Figure 1: Timmons Model for Entreprenership process

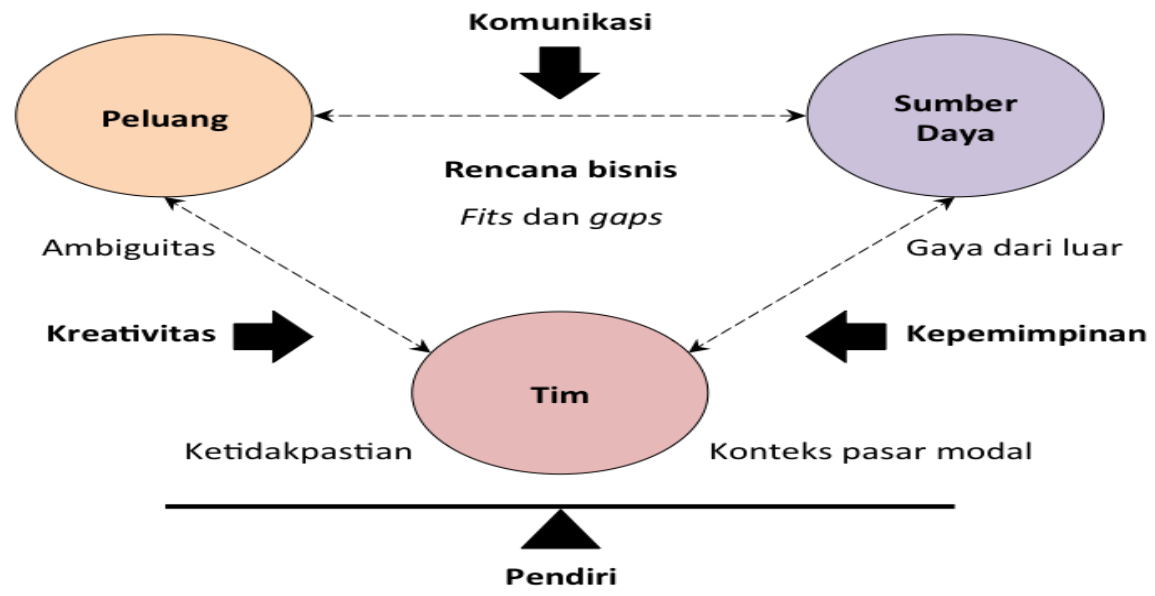

Keberlanjutan: untuk Lingkungan, Komunitas, dan Masyarakat

Sourcer: Timmons \& Spinelli (2007). 
First, the model developed by Lacho, (2010) is currently developing a model "Entrepreneurship Education" at the University of New Orleans (UNO) for two seasons. The ability specifically taught about building networking skills and negotiation, as well as intact abilities controlled by employee's compeny.Development models only attended by 10 students. The result all students were able to pass well. Researchers applied entrepreneurship by making small business on campus. 10 students on the role of the company are divided into internal and external role player. Internal role to be played are: business owners, workers, leaders, and external supervisor. They are should be played among others: customers, banks, suppliers (suppliers), the media, and others. The ability to build networks and negotiation should be developed for the business practice. As a result, this method is more effective and applicable (easy to implement) in real situations.

Second, the model developed by Kordnaeij et al. (2011), while doing research on, "Origins of Entrepreneurial Opportunities in e-Banking." The model was developed taking one of the models that have been used by Plummer (2007: 368 in Kordnaeij et al., 2011)), which illustrated that the development of entrepreneurial model can be started with: feel the entrepreneurial opportunity, entrepreneurial strategy, determine new opportunities that can be done to start a business, and the opportunity to execute it in the form of exploitation of the business which is believed can be beneficial.

Third model, Ardichvili (2003: 118 in Kordnaeij et al., 2011: 25). This model is more complicated than the models Plummer. To grow the entrepreneurial skills needed: do trait that is a treatment that appears personal creativity and a sense of optimism, forming social networks (social networks), by trying to overcome the disadvantages of self, made a number of actions (action sets), seeking partner (partnership), processing capability self constantly, preparing entrepreneurial spirit (entrepreneurial Alertness), as the core (core process) is to build a good perception (perception), find it interesting (discovery), to creations that can be profitable innovation (creation). When it was created, just developing (development), and evaluate the strengths and weaknesses, to be developed in a better shape in the future (future formation) by taking into account various types of opportunities (type of opportunity) is there.

Fourth, the model developed by the Neck, and Mayer (1998 adapted by Lacho, 2010) which is to invite students to watch the video (movie) to train some of the important concepts of entrepreneurship, so that the students themselves growing entrepreneurial mind set. Entrepreneurial mind set is very important grown in student life, so that all our thoughts, feelings, actions, speech, discussions, conduct everyday life, and the entire process in all its forms is always oriented business activities.

\section{Figure 2.Adoption Cases Study ( Yin :2009)}

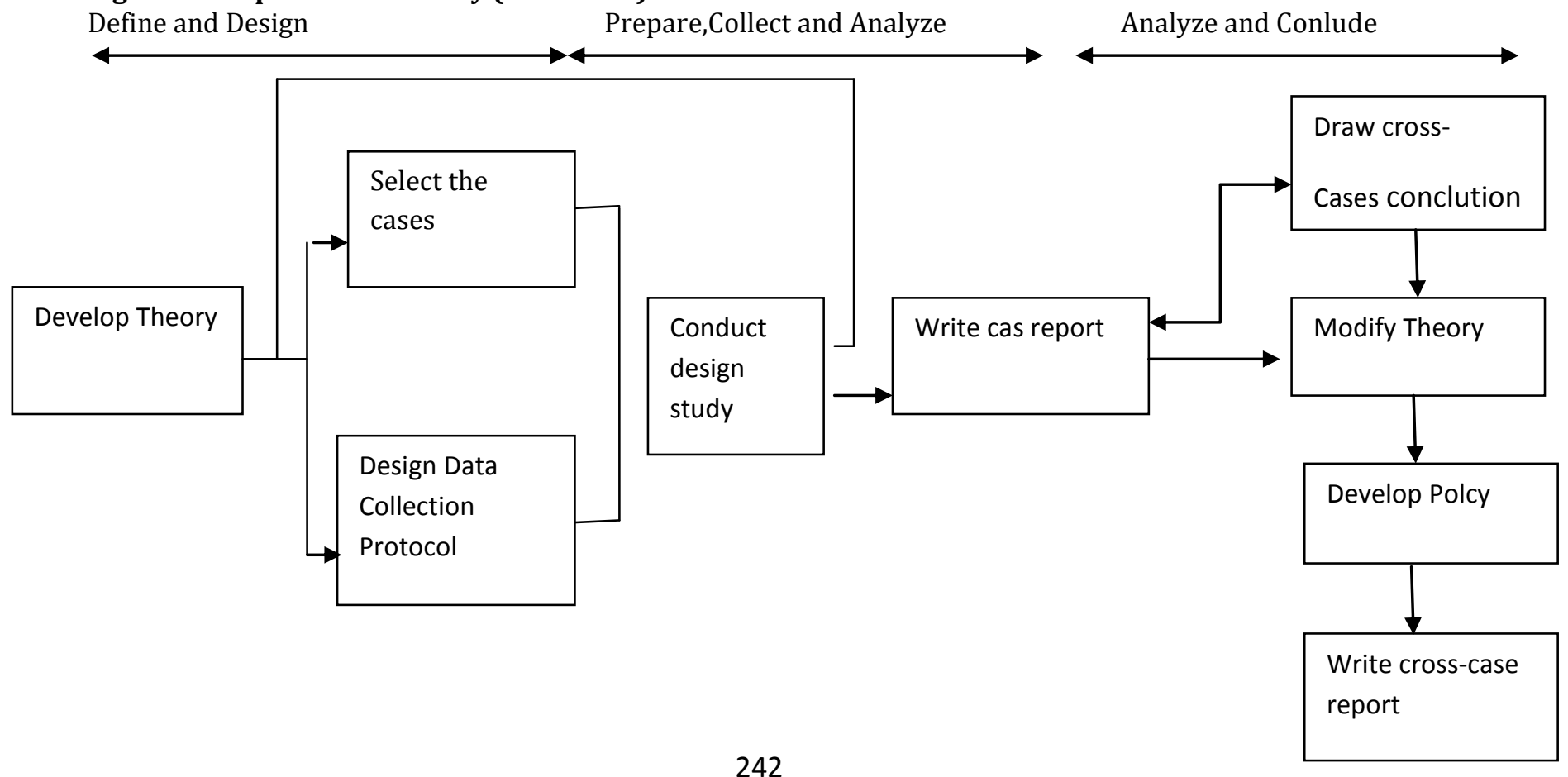




\section{Methodology}

This research is a case study (Yin, 2009). Step for case study such as : (1)Definition and research design (2)Preparing and Data Collecting and (3) Analysis and Conclution. Analysis techniques using descriptive analysis in the form of statements of research finding. The type of data collected for analysis of data consisting of primary and secondary data. Primary data was obtained through interviews and questionnaires, while secondary data obtained from the literature and the providers of training activities.

\section{Results}

Description of the training process in growing new entrepreneurs: The process of entrepreneurial learning in growing new entrepreneurs who have doing by business incubators include the recruitment process, participants, learning process and mentoring process. Business incubator selection process to acquire entrepreneurial is with predetermined criteria. The selection process includes administrative requirements, filling questionnaires and interviews entrepreneurial .Participants spread of 8 districts and is dominated by the Bandung district by 47 percent. The business sectors of participants consisted of food, beverages and convection. Training material is an innovation from the research and experience of learning to solve specific problems faced by the target. The material presented should be tailored to the needs of the target. As noted by Yager (1991), training materials submitted must be tailored to the target group and needs exercise. There are some requirements for the material is received and confirmed by the target. According to Rogers (1983) is having a higher gain than it has been adopted (absorption) Ccompliance with the habits, needs and does not conflict with the norms and the social system,complicated in technique and its implementation and easy to implementation and the results observed.The first stage of training materials delivered in fostering new entrepreneurship consists of:

- Orientation Program and Social Gathering

- Entrepreneurship and Small Business Management

- The concept of Marketing for SMEs

- Branding \& Packaging

- Simple Bookkeeping Administration

- Introduction to Business Plan

The material will be delivered well received when delivered using appropriate methods (effective and efficient) so that the objectives of the training can be achieved. The method according to Runes and Dagorbert (1963), which is a procedure used to accomplish a particular purpose ". Seeing these limits, the method of training can be defined as a procedure (levels of activity with the various means used to achieve specific goals. While the techniques are ways of connecting people (participants) with the material presented. For the method presented acceptable well, then the coach should be able to determine the methods and techniques appropriate to the circumstances and conditions of the target.

\section{Learning Methods}

Methode: The method according to Runes and Dagorbert (1963): which is a procedure used to accomplish a particular purpose ". Seeing these limits, the method of training can be defined as a procedure (levels of activity with the various means used to achieve specific goals. While the techniques are ways of connecting people (participants) with the material presented. For the method presented acceptable well, then the coach should be able to determine the methods and techniques appropriate to the circumstances of the target.The use of methods, techniques and aids specific extension will affect the effectiveness and efficiency of education, it this adjusted on several things, among others:

- The state of the target behavior,

- The state of the target adoption rate,

- The state of the message to be delivered,

- The state of the environment in which situations and extension activities

- The state of extension capabilities. 
Techniq: Teaching technicq is a way of connecting people (the study) with the material being taught. Technique is distinguished by its purpose:

- The purpose of giving information: for example, lectures, speeches, panels, and courses.

- The goal of getting the skills, such as how to demonstrations, lab exercises (role playing), socio drama.

- The purpose of using knowledge, such a discussion for troubleshooting

Source: Instructor or coach is central to the process of training. The coach is a person who has a role, task, or the potential of providing education, guidance and direction to the training participants. Coaches are required to master the material extension, specify the method used and capable or able to deliver material to the target to be easily understood and to understand. Competence and ability to run the task manager in the process of training is very important because it can influence the effectiveness some what goal training purposes. Competence relates to the formal authority to perform certain actions qualification, while the ability (ability) relates to one's ability to perform tasks according to their competence. Competence is related to aspects of the theory or science mastery, the ability to have more to do with art. As a resource on entrepreneurship training comes from practitioners, government and universities (Roges, 1983)

Mentoring: Processes or steps being taken in the learning activities / coaching incubate include: a. Stages recognition (process evaluation of the business potential and character recognition origination businesses)

b. Stages of incubation (first business facilitation, training, marketing, financing, etc.)

c. stages partnership

Assessment Criteria For Recruitment of Prospective Entrepreneur: Based on the research results criteria set for recruitment of candidates entrepreneurs are as follows:

Motivation: Motivation is one of the indicators used in determining the learning process entrepreneurship. The indicator consists of nineth motivation is achievement orientation and ambition, self-confidence and selfconfidence, perseverance, self-control, oriented toward action, a willingness to learn while working, hardworking and determination motivation.Based on result revelation motivation of respondents to the assessment showed that the orientation indicator achievement is an indicator of the dominant to be owned by the prospective entrepreneur. While lowest indicator is the willingness to learn while done. For more details are presented in the following table:

\section{Table 1: Indicators of Entrepreneurship Motivation Learning Model}

\begin{tabular}{lll}
\hline No & Criteria & Ranking \\
\hline 1 & Achievement orientation and ambition & 7,5 \\
2 & Self-confidence and self-belief & 7,75 \\
3 & Perseverance & 8 \\
4 & High internal locus of control (autonomy) & 8,25 \\
5 & Action orientation & 8,5 \\
6 & Preference for learning by doing & 8,75 \\
7 & Hardworking & 9 \\
8 & Determination & 9,25 \\
9 & Creativity & 9,5 \\
\hline
\end{tabular}


Table 2: Skills of Entrepeneurship

\begin{tabular}{lll}
\hline No & Criteria & Ranking \\
\hline 1 & Creative problem-solving & 7,25 \\
2 & Persuading & 7,5 \\
3 & Negotiating & 7,75 \\
4 & Intuitive decision making under uncertainty & 8 \\
5 & Proposing & 8 \\
6 & Holistically managing business/projects/situations & 8,25 \\
7 & Strategic thinking & 8,5 \\
8 & Selling & 8,75 \\
9 & Networking & 9,25 \\
\hline
\end{tabular}

Entrepreneurship Skills: Other indicators that are used to recruit prospective entrepreneur is entrepreneurship skills that include creative problem-solving,persudading, negotiation, decision making intuition, the ability to offer, manage business holistic, strategic thinking, and the ability to sell network development.

Business Planning Skills: Business skills as performance criteri for learning log process in growing new entrepreneurial business includes planning, financial skills, marketing, operational skills, resource skills, leadership and management skills . For more details on each of the assessment are presented in the following table of criteria

Table 3: Business skills

\begin{tabular}{lll}
\hline No & Criteria & Ranking \\
\hline 1 & Business plan & 4,25 \\
2 & Financial Skills & 4,5 \\
3 & Marketing Skills & 4,75 \\
4 & Operational Skills & 5 \\
5 & Human Resource Skills & 5,25 \\
6 & Legal Skills & 5,5 \\
7 & Communication Skills & 5,75 \\
8 & Leading Skills & 6 \\
9 & Management Skills & 6,25 \\
\hline
\end{tabular}

Based on the overall results of respondents' statements to the criteria of entrepreneurial learning models for new entrepreneurs.Showing that the criteria used for selecting entrepreneurial consists three criteria: motivation, entrepreneurial skills and business skills. Motivation is the highest criteria that must be possessed by the prospective entrepreneurs because of the presence of a strong motivation will most likely have a strong ability to do business. Entrepreneurial skills have value both of the criteria assessed. Entrepreneurial skills are skills that should be possessed by every entrepreneur. This skill is mainly associated with the skills to manage the business to be run. The third Criteria are business skills. These skills are categorized into important criteri also to be possessed by the entrepreneur, which includes the ability to manage the business internal and extern. Having a business skills course, be important as the existence of businesses owned. The bigger the business, the higher the demand for manage to business 


\section{Conclution and Recommendation}

Based on the results of the discussion of several conclusions can be drawn:

- The success of entrepreneurship learning process is carried out by taking into account various factors, namely: instructor, course to be delivered,methode that used, techniques and tools that will be used and the feedback is expected to learning process

- The criteria used for the selection of prospective entrepreneurs consist of three criteria:

a. motivation

b. entrepreneurship skills

c. business skills

- The criteria which have the highest value as a condition is a motivation, entrepreneurial skills and business skills.

- Further research is needed regarding the curriculum for entrepreneurial learning

\section{References}

Kordnaeji, A., Zali, M. R., Bavandpouri, R. A. \& Bavanpauri, R. A. (2011). Origins of Entrepreneurial Opportunities in e-Banking. Journal of Global Entrepreneurship Research, 20(1), 21-33

Curtis, E., Finch, R. J. \& Crunklin, R. (1999). Curriculum Development in Vocational and Technical Education;Planning Content and Implementaton.The University of ichigan,ISBN 0205279023

Lacho, K. J. (2010). How Small Business Owners Can Use Social Networking to Promote Their Business. The Entrepreneurial Excecutive,15, 127-133c,28-355-362

Plummer, L. A. (2007). An essay on The Origins of Entrepreneurial on Small Business. Economics, 4, 363-379

Politis, D. (2005). The Process of Entrepreneurial Learning; a Conceptual Framework. Entrepreneurship Theory and Practice, 29(4), 399-424.

Runes, L. \& Dagorbert, D. (1963). Pictorial History of Philosophy.109 RUN P Patersom,New Jersey;Littefield Adm \& Co

Yin, R. K. (2009). Case Study Research; Design and Methods.4 th.ed.Sage Ltd olivers Yard 55 City Road.London

Rogers, E. M. (1983). Diffusion and Innovation.Third Edition.The Free Press New

Shard, L. \& Polland, L. (1987). A system for Teaching Business Education .New York.Mc Graw-Hill Book Company.

Shane, S. \& Vencataraman, A. (2000). The promise of Entrepreneursship as a Field of Research. Academy of management Review, 25(1), 217-226.

Timmons, J. \& Spinelli, L. (2007). New Venture Creation :Entrepreneurship for The 21 st Century. Edtion 8.Mc Graw Hill. ISBN 9780071276230

Todaro, K. (1997). Economic For Developing Word an Introduction to Principles, Problem and Policies for Development.London.Logman Group.Ltd

Yager, R. (1991). The Contractivist Learning Model. The Science Teacher, 58(6), 52-7 